\title{
Optimizing Patient Experience by Improving Patient-Clinician Communication Through Hospital Electronic Systems
}

\author{
Nilmini WICKRAMASINGHE ${ }^{\mathrm{a}, 1}$ and Jonathan L SCHAFFER ${ }^{\mathrm{b}}$ \\ a Swinburne University of Technology \& Epworth HealthCare, Australia \\ ${ }^{\mathrm{b}}$ Cleveland Clinic, USA
}

\begin{abstract}
Providing high value care is essential in today's healthcare context. A critical aspect of this is ensuring patients have a positive patient experience. The use of electronic systems can serve as enablers in this regard as this exploratory research highlights.
\end{abstract}

Keywords. EMR, Point of Care solutions, patient experience

\section{Introduction}

Poor communication is one of the most common causes of adverse health care events, mistakes or missed care. Over the last 10 years, communication problems have been the major cause in over $70 \%$ of sentinel events [1]. At the same time we have seen an increase in the diffusion and adoption of digital solutions such as EMRs (electronic medical record systems). There is thus a need to examine how communication with electronic systems may contribute to creating opportunities for patient and family involvement to improve communication. To explores this, the following exploratory study serves to answer the research question "How can EMRs and point of care solutions facilitate better clinician-patient communication."

\section{Method}

A socio-technical systems perspective utilising a mixed method approach was adopted. The project consists of multiple phases. The objective is to investigate those elements of communication used during the provision of healthcare while using an EMR and/or a Point of Care system in hospitals in US and Australia.

Following Yin's [2] directive case studies were collected that were exemplar including representing either a public or private hospital environment and having a noted

\footnotetext{
${ }^{1}$ Corresponding Author, Nilmini Wickramasinghe, Swinburne University of Technology \& Epworth HealthCare, Australia.
} 
leadership in delivering quality care. Thematic analysis was used to uncover relevant details from semi-structured interviews.

\section{Results}

Preliminary work has been completed in this exploratory research in progress which includes a systematic review on the topic of five databases from inception of EMR or Point of Care solution to the end of 2016. After perusing 3187 papers, 22 studies were found to be relevant.

Next steps include a detailed assessment of specific sites which have a fully implemented EMR in place in both US and Australia respectively.

\section{Discussion and Conclusions}

Our initial investigation into hospital communication solutions and their adoptions has served to indicate a great need to shift beyond current data-centric concerns with making EMR/Point of Care implementations succeed, to focus on the social and organizational issues and thereby to realize the technology's potential to enhance human communication among clinicians and patients and their families. By examining this issue in two different healthcare systems; Australia and US, we add a further level of depth to the analysis.

\section{References}

[1] Manias E, Bucknall T, Wickramasinghe N, Gray K, Schaffer J, Rosenfeld E. Patient and family engagement in communicating with electronic medical records in hospitals: A systematic review. Int J Med Inform. 2020 Feb;134:104036. doi: 10.1016/j.ijmedinf.2019.104036. Epub 2019 Nov 27. PMID: 31835159. Available at https://pubmed.ncbi.nlm.nih.gov/31835159/

[2] Yin R. 2017 Case study research and applications. Sage Thousand Oaks. 